\title{
Ethanol Dependence Abolishes Monoamine and GIRK (Kir3) Channel Inhibition of Orbitofrontal Cortex Excitability
}

\author{
Sudarat Nimitvilai', Marcelo F Lopez ${ }^{2}$, Patrick J Mulholland ${ }^{1,2}$ and John J Woodward ${ }^{*, 1,2}$ \\ 'Department of Neuroscience, Medical University of South Carolina, Charleston, SC, USA; ${ }^{2}$ Department of Psychiatry and Behavioral Sciences, \\ Medical University of South Carolina, Charleston, SC, USA
}

\begin{abstract}
Alcohol abuse disorders are associated with dysfunction of frontal cortical areas including the orbitofrontal cortex (OFC). The OFC is extensively innervated by monoamines, and drugs that target monoamine receptors have been used to treat a number of neuropsychiatric diseases, including alcoholism. However, little is known regarding how monoamines affect OFC neuron excitability or whether this modulation is altered by chronic exposure to ethanol. In this study, we examined the effect of dopamine, norepinephrine, and serotonin on lateral OFC neuronal excitability in naive mice and in those exposed to chronic intermittent ethanol (CIE) treatment. All three monoamines decreased current-evoked spike firing of IOFC neurons and this action required $\mathrm{G}_{\mathrm{i} \alpha}$-coupled D2, $\alpha 2$-adrenergic, and 5HTIA receptors, respectively. Inhibition of firing by dopamine or the D2 agonist quinpirole, but not norepinephrine or serotonin, was prevented by the $\mathrm{GABA}_{A}$ receptor antagonist picrotoxin. GABA-mediated tonic current was enhanced by dopamine or the DI agonist SKF8I297 but not quinpirole, whereas the amplitude of spontaneous IPSCs was increased by quinpirole but not dopamine. Spiking was also inhibited by the direct GIRK channel activator ML297, whereas blocking these channels with barium increased firing and eliminated the inhibitory actions of monoamines. In the presence of ML297 or the G-protein blocker GDP- $\beta$-S, DA induced a further decrease in spike firing, suggesting the involvement of a non-GIRK channel mechanism. In neurons from CIE-treated mice, spike frequency was nearly doubled and inhibition of firing by monoamines or ML297 was lost. These effects occurred in the absence of significant changes in expression of $\mathrm{G}_{\mathrm{i} / \mathrm{o}}$ or GIRK channel proteins. Together, these findings show that monoamines are important modulators of IOFC excitability and suggest that disruption of this process could contribute to various deficits associated with alcohol dependence.
\end{abstract}

Neuropsychopharmacology (2017) 42, I800-18|2; doi:I0.1038/npp.2017.22; published online 15 March 2017

\section{INTRODUCTION}

Monoamine neurotransmitters such as norepinephrine (NE), serotonin $(5 \mathrm{HT})$, and dopamine (DA) are important regulators of neuronal function and are critical for a wide variety of affective behaviors including reward, attention, emotion, memory, and learning. Alterations in the levels or function of monoamines and their receptors, either by disease or genetic differences, are thought to contribute to symptoms associated with many psychiatric diseases including addiction (Kirby et al, 2011; Narendran et al, 2014; Volkow et al, 2001). Indeed, drugs that target monoamine systems have long been used to treat affective and attention disorders (Rothman et al, 2008; Volkow et al, 2002).

The ability of these compounds to partially alleviate symptoms of psychiatric diseases is thought to largely reflect actions on neurons and circuits within the frontal cortex. Of these, the orbitofrontal cortex (OFC) is known to play an important role in integrating information from sensory

* Correspondence: Dr IJ Woodward, Department of Neuroscience, Medical University of South Carolina, 67 President Street, IOP456N, Charleston, SC 29425, USA, Tel: 843792 5225, Fax: 843792 7353,

E-mail: woodward@musc.edu

Received 10 August 2016; revised 18 January 2017; accepted 21 January 2017; accepted article preview online 31 January 2017 modalities in order to guide behavior based on optimal choices and outcomes. Thus, regions of the OFC mediate aspects of choice behavior (Roesch and Olson, 2007; Schoenbaum et al, 1998), reversal learning (Bissonette et al, 2008; McAlonan and Brown, 2003), and the development of anticipation in response to either appetitive or aversive stimuli (Tremblay and Schultz, 1999). Dysfunction of the OFC is associated with numerous neuropsychiatric diseases including obsessive-compulsive disorder and symptoms of OFC deficiency are often observed in individuals suffering from alcohol and drug abuse disorders (Fortier et al, 2008; Verdejo-Garcia et al, 2006). In a previous report, we showed that alcohol-dependent mice have impaired performance on a reversal learning task (Badanich et al, 2011) that in both rodents (Brown et al, 2007) and primates (Jedema et al, 2011) requires the OFC. Withdrawal from repeated cycles of chronic intermittent ethanol exposure was also shown to enhance the intrinsic excitability of OFC neurons (Nimitvilai et al, 2016), suggesting that dysregulation of processes that modulate excitability may contribute to dysfunction associated with alcohol use disorders. Understanding the mechanisms that regulate OFC excitability is thus important for developing therapeutic interventions designed to restore normal control of neuronal activity. 
The OFC has been shown to be extensively innervated by monoamine neurotransmitters (Agster et al, 2013; Homayoun and Moghaddam, 2008; Robbins and Arnsten, 2009) and dysregulation of monoamine function has been suggested to underlie deficits in certain OFC-dependent behaviors (Clarke et al, 2005; Kheramin et al, 2004; Winstanley et al, 2006). However, virtually nothing is known regarding the functional effects of monoamines on the excitability of OFC neurons or whether this modulation is affected by prior exposure to ethanol. In this study, we used whole-cell patch-clamp electrophysiology to examine the effects of DA, NE, and 5HT on the intrinsic excitability of lateral OFC (IOFC) neurons and determined whether the actions of these modulators are altered in ethanol-dependent mice. The results demonstrate that monoamine neurotransmitters reduce excitability via activation of $G$ proteincoupled inwardly rectifying potassium (GIRK; Kir3 family) channels and that this regulation is lost in mice made dependent on alcohol.

\section{MATERIALS AND METHODS}

\section{Animals}

Male C57BL/6J mice were obtained from Jackson Laboratories (Bar Harbor, ME) (https://www.jax.org/strain/00064) at 9 weeks of age. They were group-housed (4/cage) and allowed to acclimatize to the colony room for at least 1 week in a temperature- and humidity-controlled AAALACapproved facility. Animals were maintained on a $12 \mathrm{~h}$ light/ dark cycle with lights off at $0900 \mathrm{~h}$ and had ad libitum access to food and water. All animals were treated in strict accordance with the NIH Guide for the Care and Use of Laboratory Animals and all experimental methods were approved by the Medical University of South Carolina's institutional animal care and use committee.

\section{Chronic Intermittent Ethanol Exposure}

After acclimatization, mice were exposed to four cycles of chronic intermittent ethanol (CIE group) vapor or air (control) in inhalation chambers as previously described (Badanich et al, 2011; Nimitvilai et al, 2016). Briefly, each cycle consisted of daily exposure to ethanol vapor for $16 \mathrm{~h}$ followed by $8 \mathrm{~h}$ of abstinence in the home cage. This was repeated each day for 4 consecutive days followed by 3 days of abstinence before beginning the next cycle of ethanol exposure. The average BEC during the 4 weeks of CIE exposure was $196.76 \pm 9.69 \mathrm{mg} / \mathrm{dl}$. Mice were killed 3, 7, or 14 days following the final vapor exposure (ethanol or air) and used for electrophysiological and biochemical studies. Full details are provided in Supplementary Materials.

\section{Brain Slice Electrophysiology}

Whole-cell patch-clamp electrophysiology recordings were carried out in brain slices containing the IOFC as previously described (Badanich et al, 2013). Briefly, recordings were localized to deep layers of the lOFC and current-clamp recordings used a potassium gluconate internal solution (in $\mathrm{mM}$; $120 \mathrm{~K}$-Gluconate, $10 \mathrm{KCl}, 10 \mathrm{HEPES}, 2 \mathrm{MgCl}_{2}$, 1 EGTA, $2 \mathrm{NaATP}$, and 0.3 NaGTP, adjusted to $294 \mathrm{mOsm}, \mathrm{pH}=7.4$ ).
In some experiments, GDP- $\beta$-S $(500 \mu \mathrm{M})$ was included in the potassium gluconate internal solution to examine a role for G-protein activation on AP spiking. For voltage-clamp experiments, a cesium chloride internal solution (in $\mathrm{mM}$; $120 \mathrm{CsCl}, 10$ HEPES, $2 \mathrm{MgCl}_{2}$, 1 EGTA, $2 \mathrm{NaATP}, 0.3$ NaGTP, and 1 QX-314, adjusted to $294 \mathrm{mOsm}, \mathrm{pH}=7.4$ ) was used. To measure spontaneous inhibitory postsynaptic currents (sIPSCs), the glutamate NMDA antagonist DL-AP5 $(100 \mu \mathrm{M})$ and AMPA antagonist CNQX $(10 \mu \mathrm{M})$ were added to the aCSF perfusion solution to isolate $\mathrm{GABA}_{\mathrm{A}}$-mediated currents, and the neuron was voltage clamped at $-70 \mathrm{mV}$. Spontaneous events were detected using a template matching algorithm and a threshold amplitude of $10 \mathrm{pA}$ (AxographX software, Axograph, Sydney, Australia). All whole-cell recordings were carried out using an Axon MultiClamp 700B amplifier (Molecular Devices, Union City, CA) interfaced with an Instrutech ITC-18 analog-digital converter (HEKA Instruments, Bellmore, NY). Data were acquired with AxographX software running on a Macintosh G4 computer (Apple, Cupertino, CA). Events were filtered at $4 \mathrm{kHz}$ and digitized at a sampling rate of $10 \mathrm{kHz}$. Full details can be found in Supplementary Materials.

\section{Drugs}

Dopamine hydrochloride was purchased from Alfa Aesar (Ward Hill, MA). Serotonin hydrochloride, $\alpha$-methyl-5HT, SKF81297, quinpirole hydrochloride, sulpiride, SCH23390, WAY100635, yohimbine, picrotoxin, naftopidil hydrochloride, nomifensine, DL-AP5, and CNQX were purchased from Tocris Biosciences (Minneapolis, MN). ML297 was purchased from Abcam (Cambridge, MA). GDP- $\beta$-S was purchased from Santa Cruz Biotechnology (Dallas, TX). Norepinephrine, strychnine, barium, and all reagents used to prepare aCSF, sucrose-containing and internal pipette solution were purchased from Sigma (St Louis, MO).

\section{Western Blotting}

OFC tissue punches were collected from control and CIEtreated mice at 3 days following the last exposure and western blotting was performed according to standard immunoblotting procedures described previously (McGuier et al, 2015). Full details can be found in Supplementary Materials.

\section{Statistical Analysis}

Experimental data are expressed as mean \pm SEM and were analyzed with Prism software (GraphPad Software, San Diego, CA) using standard methods (one-way repeated measures ANOVA, two-way ANOVA, and $t$-test) as indicated. Comparisons were considered significantly different when $p<0.05$.

\section{RESULTS}

Monoamines Decrease the Excitability of Lateral OFC Neurons through $G_{i / o}$ Linked Receptors

Dopamine. Recordings were carried out in large, regular spiking pyramidal neurons located in deep layers of the 

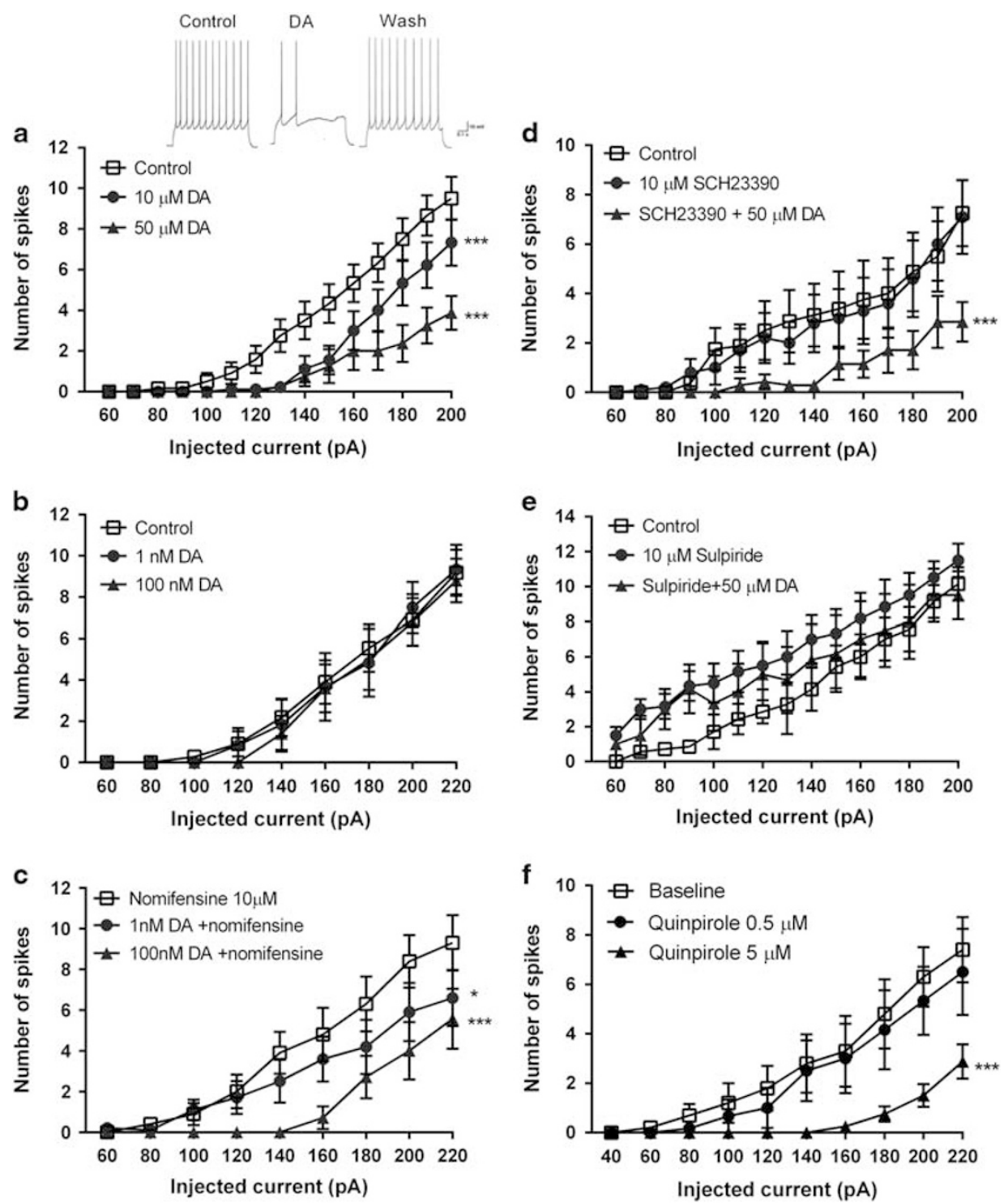

Figure I Acute dopamine application decreases current-induced spiking of lateral OFC neurons via D2 receptors. Representative traces show decreased action potential (AP) spiking in the presence of $50 \mu \mathrm{M}$ DA as compared with control. (a) Effect of dopamine (I0 and $50 \mu \mathrm{M}$ ) on AP spiking (mean \pm SEM) induced by a series of current injections (60-200 pA) in IOFC neurons. In comparison with control, DA produced a significant decrease in basal firing rates of IOFC neurons (two-way ANOVA: main effect of DA, $F_{(2,390)}=42.14, p=0.0002$; post hoc comparison, control vs DA, **** $p<000$ I). (b) Low concentrations ( $I$ and $100 \mathrm{nM}$ ) of DA did not alter the AP spiking of IOFC neurons (two-way ANOVA: main effect of DA, $F_{(2,171)}=0.036, p=0.737$; post hoc comparison, control vs DA, p > 0.99). (c) In the presence of a monoamine transporter inhibitor nomifensine $(10 \mu M), D A$ at I nM (two-way ANOVA, $F_{(2.216)}=\mid 3.9$, $q=2.55$, $* p<0.05$ ) or at $100 \mathrm{nM}$ (two-way ANOVA, $\mathrm{F}_{(2,216)}=13.9, q=5.27$, $* * * * p<0.000 \mathrm{I}$ ) produced a significant reduction in firing. (d) The DI receptor blocker SCH23390 (IO HM) had no effect on DA-induced inhibition; a significant reduction of spiking was observed when a combination of DA and SCH23390 was applied (two-way ANOVA, $F_{(2,375)}=16.25$, **** $p<0.000$ I). SCH23390 alone did not alter the cell firing. (e) The D2 receptor blocker sulpiride $(10 \mu \mathrm{M})$ suppressed DA-induced inhibition of evoked spiking so that the number of spikes in response to a series of injected current were not significantly different from sulpiride baseline (two-way ANOVA, $F_{(2,240)}=11.58, q=3.078, p>0.05$ ). Sulpiride by itself produced a small but significant increase in firing rate (two-way ANOVA, $F_{(2,240)}=11.58, q=6.89, p<0.00 I$ ). (f) The D2 receptor agonist quinpirole produced a significant decrease in number of spikes in a concentration-dependent manner (two-way ANOVA: main effect of DA, $F_{(2,210)}=19.46$, p $<0.00$ l; post hoc comparison, control vs quinpirole, $* * * * 000$ I).

lOFC. Supplementary Table 1 shows values for resting membrane potential and input resistance in the absence and presence of monoamines. In current-clamp mode, injections of current evoked increasing numbers of action potentials (APs) in lOFC neurons (Figure 1a). Action potential firing was reduced by dopamine in a concentration-dependent manner (two-way ANOVA: main effect of dopamine, $\left.\mathrm{F}_{(2,390)}=42.14, p=0.0002\right)$ and this effect was reversed upon washout. The post hoc comparisons reported significant differences in spiking in response to either $10 \mu \mathrm{M}(q=8.426$, $p<0.0001 ; N=9)$ or $50 \mu \mathrm{M}$ dopamine $(q=12.99, p<0.0001$; $N=8$ ). Concentrations of dopamine below $10 \mu \mathrm{M}$ had little effect on firing (Figure 1b; two-way ANOVA, $\left.\mathrm{F}_{(2,171)}=0.3058, p=0.737\right)$. To assess whether this reflects active uptake in the slice, recordings were carried out in the presence of the nonspecific monoamine transporter inhibitor 

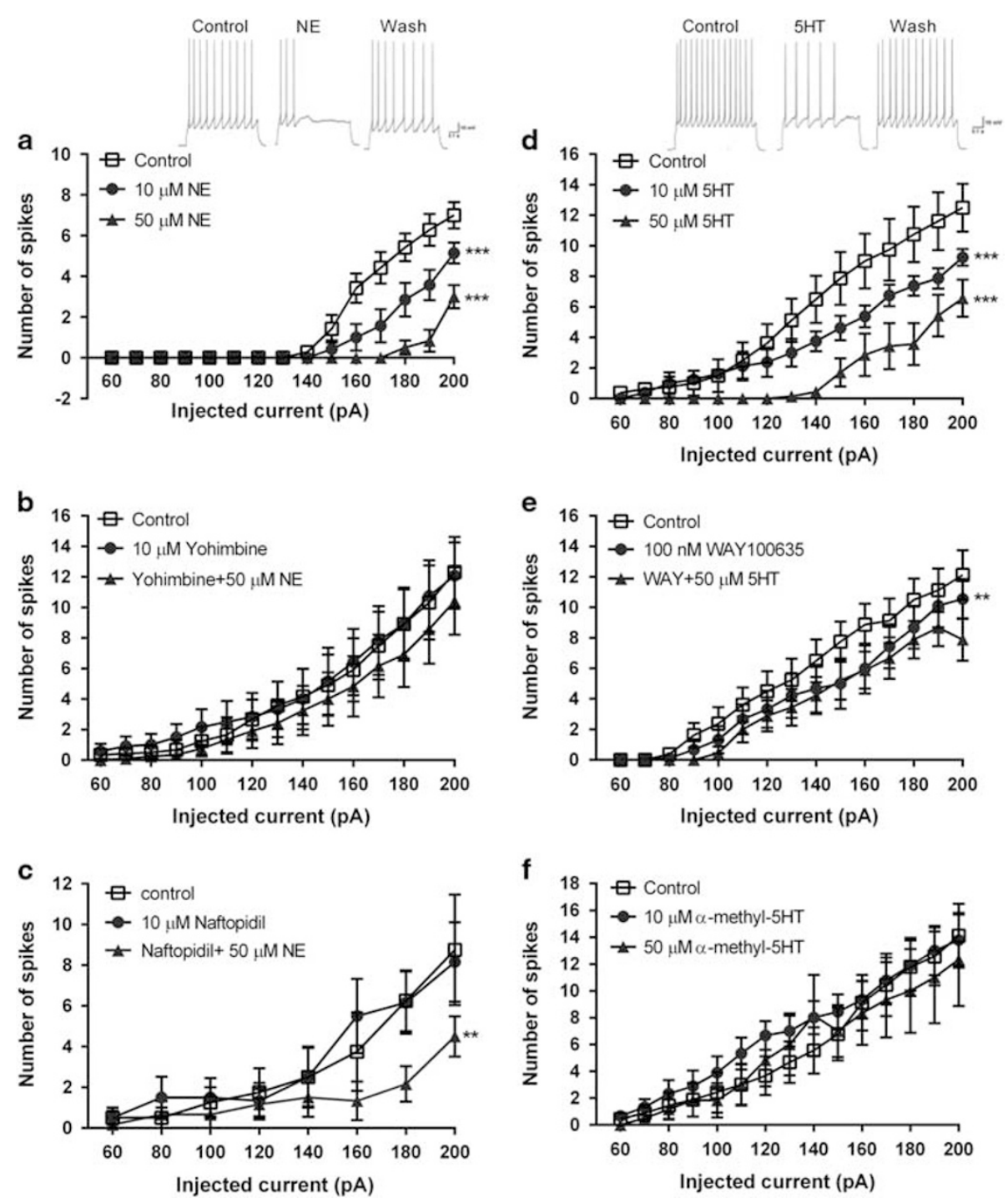

Figure 2 Acute application of norepinephrine or serotonin decreases current-induced spiking of lateral OFC neurons via $\alpha 2$-adrenergic or $5 \mathrm{HTIA}$ receptors, respectively. Representative traces show decreased action potential (AP) spiking in the presence of $50 \mu \mathrm{M}$ NE or $5 \mathrm{HT}$ as compared with control. (a) Effect of NE (10 and $50 \mu \mathrm{M})$ on AP spiking (mean \pm SEM) induced by a series of current injections (60-200 pA) in IOFC neurons. NE significantly decreased current-evoked spiking in a concentration-dependent manner (two-way ANOVA: main effect of NE, $F_{(2,255)}=60.1$ I, ***** $p<0.000$ I; post hoc comparison, control vs NE, **** $<000 \mathrm{I}$ ). (b) The $\alpha 2$-adrenergic receptor blocker yohimbine $(10 \mu \mathrm{M})$ by itself did not alter cell firing (two-way ANOVA, $\left.F_{(2,495)}=2.40 \mathrm{I}, q=0.544, p=0.0917\right)$, but it suppressed NE-induced inhibition of spiking so that the level of reduction was not statistically different from those produced by yohimbine alone (two-way ANOVA, $\mathrm{F}_{(2,495)}=2.40 \mathrm{I}, q=2.1 \mathrm{I}, p=0.09$ I7). (c) The $\alpha \mid$-adrenergic receptor blocker naftopidil ( 0 uM) did not alter spike firing (two-way ANOVA, $\left.F_{(14,140)}=0.7912, p=0.6766\right)$ and did not suppress NE inhibition of spike firing; a significant reduction in AP spiking was found when a combination of NE and naftopidil was applied (two-way ANOVA, $F_{(14,140)}=0.79 \mid 2$, *** $<0.0 \mathrm{I}$ ). (d) Effect of $5 \mathrm{HT}$ (I0 and $50 \mu \mathrm{M}$ ) on AP spiking (mean \pm SEM) induced by a series of current injections (60-200 pA). 5HT produced a significant decrease in current-evoked spiking in a concentrationdependent manner (two-way ANOVA: main effect of $5 \mathrm{HT}, \mathrm{F}_{(2,300)}=55$, ***** $p<0.000 \mathrm{I}$; post hoc comparison, control vs $5 \mathrm{HT}$, ***** $<<000 \mathrm{I}$ ). (e) The $5 \mathrm{HTI} \mathrm{A}$ receptor antagonist WAY 100635 ( I $00 \mathrm{nM}$ ) attenuated spike inhibition by $50 \mathrm{HM} 5 \mathrm{HT}$ so that the number of spikes mediated by WAY I 00365 plus $5 \mathrm{HT}$ did not differ from those mediated by WAY I 00635 alone (two-way ANOVA, $F_{(2,345)}=11.04, q=2.231$ p $>0.05$ ). The WAY I 00635 by itself slightly decreased AP firing of IOFC neurons (two-way ANOVA, $F_{(2,345)}=11.04, q=4.298$, $* * *<0.01$ ). (f) In comparison with control, no changes in AP spiking induced by an agonist of 5HT2 receptor $\alpha$-methyl-5HT at 10 and $50 \mu \mathrm{M}$ was observed (two-way ANOVA, $\mathrm{F}_{(2,315)}=2.52, p>0.05$ ).

nomifensine $(10 \mu \mathrm{M})$. With nomifensine present (Figure 1c), firing was significantly decreased by dopamine concentrations as low as $1 \mathrm{nM}$ (two-way ANOVA, $\mathrm{F}_{(2,216)}=13.9$, $q=2.55, p<0.05 ; N=10$ ) and $100 \mathrm{nM}$ (two-way ANOVA, $\left.\mathrm{F}_{(2,216)}=13.9, q=5.27, p<0.0001 ; N=7\right)$, suggesting that monoamine transporters actively regulate extracellular levels of dopamine in the cortical slice. Nomifensine itself caused a small but significant decrease in AP spiking (two-way ANOVA, $\mathrm{F}_{(1,12)}=15.2, p=0.002 ; N=13$; data not shown).
To determine whether dopamine inhibition of firing was receptor dependent, action potentials were recorded in the presence of D1 or D2 receptor antagonists. In the presence of the D1 receptor antagonist SCH23390, $50 \mu \mathrm{M}$ dopamine still produced a significant reduction in AP spiking of lOFC neurons (Figure 1d; two-way ANOVA, $\mathrm{F}_{(2,375)}=16.25$, $q=6.621, p<0.0001 ; N=8)$. SCH23390 alone did not alter cell firing (two-way ANOVA, $\mathrm{F}_{(2,375)}=16.25, \mathrm{q}=0.759$, $p>0.05)$. In contrast, dopamine $(50 \mu \mathrm{M})$ had no effect on 
spiking in the presence of the D2 receptor antagonist sulpiride (Figure 1e; two-way ANOVA, $\mathrm{F}_{(2,240)}=11.58$, $q=3.078, p>0.05 ; N=6$ ). Alone, sulpiride produced a slight, but significant, increase in firing rate (two-way ANOVA,
$\left.\mathrm{F}_{(2,240)}=11.58, q=6.89, p<0.0001\right)$, suggesting that these receptors may be tonically active in the slice. In concert with these findings, activation of D2 receptors directly with the selective agonist quinpirole also significantly reduced firing
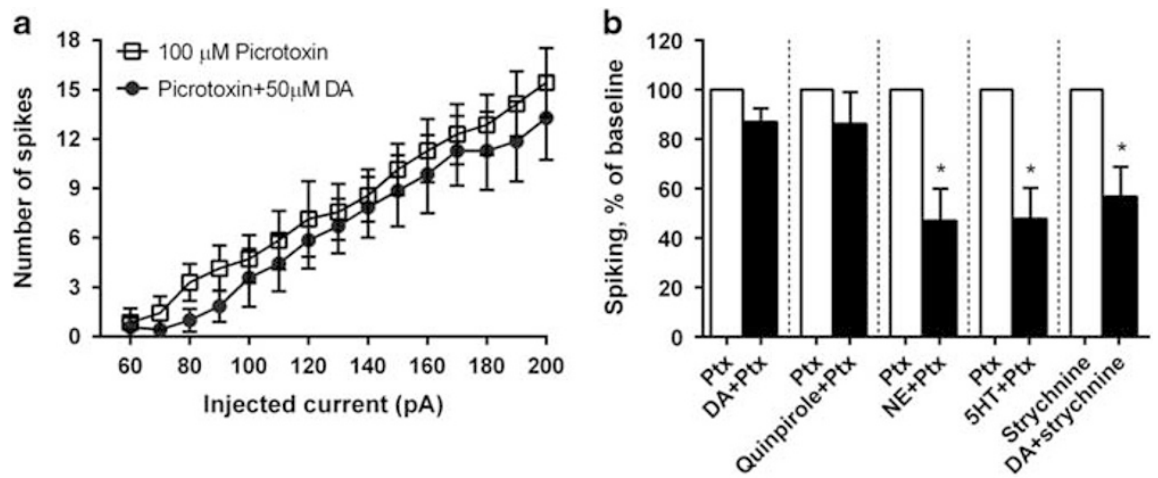

c

d
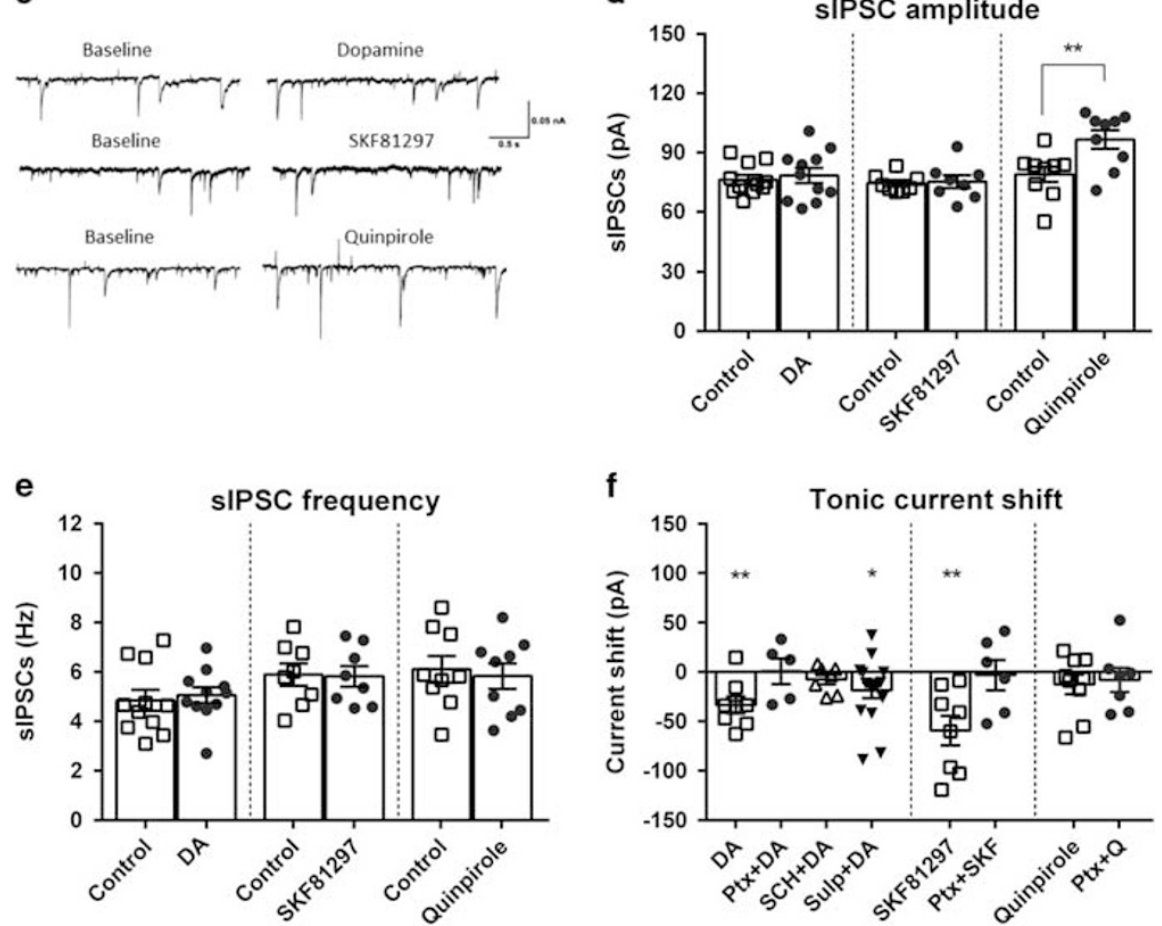

Figure 3 Effects of dopamine and DI/D2 agonists on synaptic and extrasynaptic GABA $A$ currents. (a) Picrotoxin (Ptx) attenuates the inhibitory effects of DA and quinpirole, but not NE and 5HT. Effect of Ptx and DA on AP spiking (mean \pm SEM) induced by a series of current injections (60-200 pA) in IOFC neurons. In comparison with Ptx baseline, no difference in basal firing rates of IOFC neurons was observed when DA was added in the presence of Ptx (two-way ANOVA, $F_{(14,180)}=0.0624, p>0.9999$ ). (b) Numbers of spikes at the highest current injection are compared as the percent change from Ptx or strychnine baseline in response to each drug treatment condition. In comparison with Ptx alone, no difference in number of spikes was observed when Ptx was added together with DA (two-tail paired $t$-test, $t(6)=2.396, p=0.0536$ ) or quinpirole (two-tail paired $t$-test, $t(5)=1.077, p=0.3306$ ). However, $N E$ (two-tail paired $t$-test, $t(5)=4.113, * p=0.0092$ ) or $5 \mathrm{HT}$ (two-tail paired $t$-test, $t(5)=4.175, * p=0.0087$ ) significantly decreased the cell firing as compared with Ptx baseline. With strychnine, DA produced a significant decrease in AP spiking as compared with strychnine alone (two-tail paired $t$-test, $t(5)=3.6 \mid 4$, $* p=0.0153$ ). (c) Representative traces of sIPSCs in the absence (baseline) and presence of DA, SKF8I 297 or quinpirole are shown. Graphs display individuals and mean ( \pm SEM) changes in sIPSC amplitude (d) and sIPSC frequency (e). In comparison with control, application of dopamine (50 $\mu$ M) did not alter sIPSC amplitude ( $c$, two-tailed $t$-test, $t(10)=0.6305, p=0.5425$ ) or frequency ( $d$, two-tail paired $t$-test, $t(I 0)=0.5298, p=0.6078)$. Similarly, no change in sIPSC amplitude (c, two-tailed $t$-test, $t(7)=0.1762, p=0.865 \mathrm{I}$ ) or frequency $(\mathrm{d}$, two-tail paired $t$-test, $t(7)=0.4763, p=0.6484$ ) was observed when SKF8I 297 was applied. Quinpirole $(5 \mu M)$ significantly enhances sIPSC amplitude (c, two-tailed $t$-test, $t(8)=3.61$, *** $p=0.0069$ ), but had no effect on sIPSC frequency ( $d$,

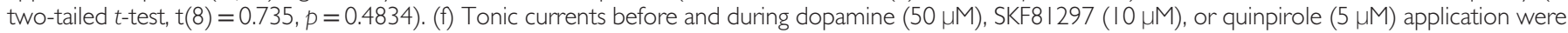
measured. Dopamine induced a significant increase in the holding current of IOFC neurons (two-tailed $t$-test, $t(7)=3.932$, $* * *=0.0057)$ and this effect was blocked by picrotoxin ( $100 \mu \mathrm{M}$; two-tailed $t$-test, $t(4)=0.054, p=0.9595$ ) or SCH23390 (two-tailed $t$-test, $t(6)=1.457$, $p=0.1953$ ), but not sulpiride (twotailed $t$-test, $t(I 5)=2.252$, $* p=0.0397$ ). Similarly, SKF8I 297 significantly enhanced tonic current (two-tailed $t$-test, $t(7)=3.945$, $* * p=0.0056)$ and this effect was suppressed by picrotoxin (two-tailed $t$-test, $t(5)=0.2097, p=0.8422$ ). No change in tonic current was observed when quinpirole was applied (two-tailed $t$-test, $t(8)=1.252, p=0.2458$. 
(Figure 1f; two-way ANOVA: main effect of quinpirole, $\left.\mathrm{F}_{(2,210)}=19.46, \quad p<0.0001\right)$. The post hoc comparisons reported significant differences in spiking in response to $5 \mu \mathrm{M}$ quinpirole $(q=6.09, p<0.0001 ; N=8)$.

Norepinephrine. Similar to dopamine, acute application of either 10 or $50 \mu \mathrm{M}$ NE produced a robust inhibition of AP spiking in lOFC neurons (two-way ANOVA, main effect of $\left.\mathrm{NE}, \mathrm{F}_{(2,255)}=60.11, p<0.0001\right)$ and this effect reversed after washout. The post hoc comparisons showed significant decreases in firing in response to either $10 \mu \mathrm{M}(q=9.089$, $p<0.0001 ; N=7$ ) or $50 \mu \mathrm{M}$ NE (Figure $2 \mathrm{a} ; q=15.25$, $p<0.0001 ; N=6)$. Application of the $\alpha-2$ adrenergic receptor antagonist yohimbine $(10 \mu \mathrm{M})$ alone did not alter the excitability of 1OFC neurons (two-way ANOVA, $\left.\mathrm{F}_{(2,495)}=2.401, q=0.544, p=0.0917\right)$ but it did suppress $\mathrm{NE}$ inhibition of spiking (Figure 2b; two-way ANOVA, $\left.\mathrm{F}_{(2,495)}=2.401, q=2.11, p=0.0917 ; N=12\right)$. In contrast, the reduction in firing by $\mathrm{NE}$ was not reduced by the $\alpha 1$ adrenergic receptor antagonist naftopidil $(10 \mu \mathrm{M})$ (Figure 2c; two-way ANOVA, $\mathrm{F}_{(2,104)}=6.223, q=3.306, p<0.01 ; N=6$ ) and by itself, naftopidil had no effect on spiking (two-way ANOVA, $\left.F_{(2,104)}=6.223, q=0.3779, p=0.6766\right)$.

Serotonin. As summarized in Figure $2 \mathrm{~d}$ and similar to that observed for DA and NE, acute application of serotonin reversibly decreased AP spiking of $1 \mathrm{OFC}$ neurons in a concentration-dependent manner (two-way ANOVA, main effect of $\left.5 \mathrm{HT}, \mathrm{F}_{(2,300)}=55, p=0.0314 ; N=8\right)$. The post hoc comparisons showed significant decreases in spiking in response to either $10 \mu \mathrm{M}(q=6.831, p<0.0001)$ or $50 \mu \mathrm{M}$ $(q=14.64, p<0.0001)$ serotonin. This effect was blocked by the $5 \mathrm{HT}_{1 \mathrm{~A}}$ antagonist WAY100635 (100 nM; two-way ANOVA, $\mathrm{F}_{(2,345)}=11.04, q=2.231, p>0.05$, Figure $\left.2 \mathrm{e}\right)$ that itself produced a small decrease in firing rate (two-way ANOVA, $\left.\mathrm{F}_{(2,345)}=11.04, q=4.298, p<0.01\right)$. As there is also evidence for $5 \mathrm{HT}_{2}$ receptors in the OFC, we tested whether selectively activating these receptors would influence lOFC neuronal excitability. There was no significant change in AP firing of lOFC neurons in the presence of $10 \mu \mathrm{M}(N=9)$ or $50 \mu \mathrm{M}(N=6)$ of the $5 \mathrm{HT}_{2}$ agonist $\alpha$-methyl-5HT (Figure 2f; two-way ANOVA, $\left.\mathrm{F}_{(2,315)}=2.52, p>0.05\right)$.

\section{Involvement of $\mathrm{GABA}_{\mathrm{A}}$ Receptors in Monoamine Inhibition of 10FC Neuronal Excitability}

To explore potential mechanisms underlying monoamine inhibition of $1 \mathrm{OFC}$ firing, we investigated whether $\mathrm{GABA}_{\mathrm{A}}$ receptors were involved as previous studies report that monoamines can potentiate $\mathrm{GABA}_{\mathrm{A}}$-induced inhibition of neurons in the PFC (Zhou and Hablitz, 1999) and other brain areas (Hoerbelt et al, 2015; Janssen et al, 2009; Rainnie, 1999). Recordings were performed in the presence of a $\mathrm{GABA}_{\mathrm{A}}$ receptor blocker picrotoxin $(100 \mu \mathrm{M})$ in the aCSF, and the effect of each monoamine was reexamined. With picrotoxin present, $50 \mu \mathrm{M}$ dopamine no longer inhibited current-evoked spiking of lOFC neurons (Figure 3a; two-way ANOVA, $\left.F_{(1,180)}=0.0624, p=0.99 ; N=7\right)$. Similarly, the inhibitory effect of the D2 receptor agonist quinpirole $(5 \mu \mathrm{M})$ was also blocked by picrotoxin (Supplementary Figure S1a; two-way ANOVA, $\left.\mathrm{F}_{(1,100)}=0.011, p=0.9153 ; N=6\right)$. In contrast, the inhibition of AP spiking by $50 \mu \mathrm{M}$ norepinephrine (Supplementary Figure S1b; two-way ANOVA, $\mathrm{F}_{(1,150)}=101.4, p<0.0001 ; N=6$ ) or serotonin (Supplementary Figure S1c; two-way ANOVA, $\mathrm{F}_{(1,300)}=31.4, p<0.0001$; $N=10$ ) was not affected by picrotoxin. In addition to $\mathrm{GABA}_{\mathrm{A}}$ receptors, picrotoxin also inhibits glycine-activated chloride channels (Wang et al, 2006) and we previously reported a glycine-mediated inhibition of neuronal firing in the lOFC (Badanich et al, 2013). To investigate whether glycine receptors have a role in dopamine-mediated inhibition of spike firing, recordings were carried out in the presence of strychnine. There was no change in dopamine inhibition of lOFC firing by strychnine $(1 \mu \mathrm{M})$ (Supplementary Figure S1d, two-way ANOVA, $\mathrm{F}_{(1,150)}=56.83$, $p<0.0001 ; N=6)$. Summarized in Figure $3 \mathrm{~b}$ are the number of spikes at the highest current injection step in the presence of picrotoxin or strychnine and each monoamine $(50 \mu \mathrm{M})$ and data are normalized to the picrotoxin or strychnine baseline.

To further probe how $\mathrm{GABA}_{\mathrm{A}}$ receptors are involved in the dopamine inhibition of $1 \mathrm{OFC}$ neuronal firing, we monitored sIPSCs and tonic current before and during exposure to dopamine, the D1 agonist SKF81297, or the D2 agonist quinpirole. In these experiments, a cesium chloride internal solution was used and voltage-clamp recordings were carried out in the presence of glutamate receptor antagonists (CNQX and AP5) to isolate $\mathrm{GABA}_{\mathrm{A}}$-mediated events. Interestingly, application of dopamine $(50 \mu \mathrm{M})$ had no significant effect on sIPSC amplitude (Figure $3 c$ and $d$; two-tail paired $t$-test, $t(10)=0.6305, p=0.5425$ ) or frequency (Figure $3 \mathrm{c}$ and e; two-tail paired $t$-test, $t(10)=0.5298$, $p=0.6078)$ when compared with data from control recordings. Similarly, the D1 agonist SKF81297 $(10 \mu \mathrm{M})$ did not alter sIPSC amplitude (two-tail paired $t$-test, $t(7)=0.1762$, $p=0.8651$ ) or frequency (two-tail paired $t$-test, $t(7)=0.4763$, $p=0.6484$ ) when compared with the control baseline. In contrast, the D2 agonist quinpirole $(5 \mu \mathrm{M})$ significantly increased the amplitude of sIPSCs (Figure $3 \mathrm{c}$ and $\mathrm{d}$; two-tail paired $t$-test, $t(8)=3.61, p=0.0069)$, whereas it had no effect on frequency (Figure $3 \mathrm{c}$ and e; two-tail paired $t$-test, $t(8)=0.735, p=0.4834)$.

To assess whether these dopamine receptor agonists also show differential effects on tonic currents mediated by extrasynaptic $\mathrm{GABA}_{\mathrm{A}}$ receptors, we measured the holding current before and during local application of DA, SKF81297, or quinpirole. DA $(50 \mu \mathrm{M})$ induced a significant increase in the holding current of lOFC neurons (Figure 3f; two-tailed $t$-test, $t(7)=3.932, p=0.0057$ ) and this effect was blocked by picrotoxin $(100 \mu \mathrm{M}$; two-tailed $t$-test, $t(4)=0.054$, $p=0.9595)$. Similarly, the D1 agonist SKF81297 $(10 \mu \mathrm{M})$ significantly increased tonic current (two-tailed $t$-test, $t(7)=3.945, p=0.0056)$ and this increase was also suppressed by picrotoxin (two-tailed $t$-test, $t(5)=0.2097$, $p=0.8422$ ). However, there was no change in tonic current during application of quinpirole $(5 \mu \mathrm{M})$ to the patched neuron (two-tailed $t$-test, $t(8)=1.252, p=0.2458$ ). Blocking D1 receptors with $\mathrm{SCH} 23390$ attenuated DA enhancement of tonic current (two-tailed $t$-test, $t(6)=1.457, p=0.1953$ ), whereas blocking D2 receptors with sulpiride had no effect on DA-induced tonic currents (two-tailed $t$-test, $t(15)=2.252, p=0.0397)$. 

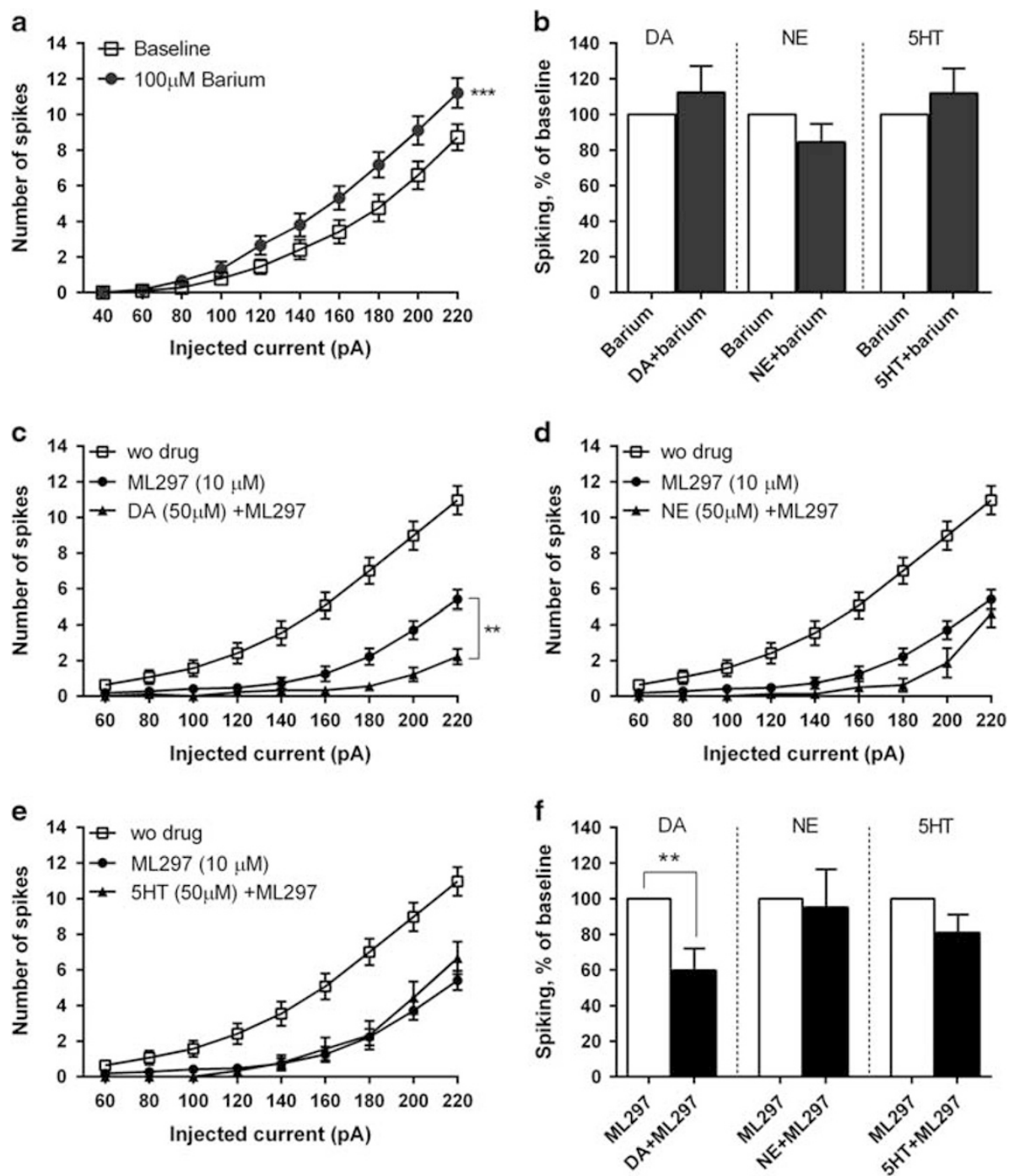

Figure 4 Inhibition of GIRK channels attenuates the inhibitory effects of monoamines. (a) Number (mean \pm SEM) of spikes from IOFC neurons plotted against a series of current injections. The GIRK channel inhibitor barium (I00 $\mathrm{MM}$ ) caused a slight but significant increase in spiking when compared with control (two-way ANOVA, $F_{(I, 560)}=27.2$, **** $p<0.0001$ ). (b) Numbers of spikes at the highest current injection are compared as percent change from barium baseline in response to each drug treatment condition. In comparison with barium alone, no difference in number of spikes was observed when barium was added together with DA (two-tail paired $t$-test, $t(4)=0.85, p=0.4438), N E(n=6$, two-tail paired $t$-test, $t(5)=1.52, p=0.1889)$, or $5 \mathrm{HT}$ (two-tail paired $t$-test, $t(5)=0.86, p=0.4292)$. ( $c-e)$ Number (mean \pm SEM) of spikes from IOFC neurons plotted against a series of current injections. A GIRK channel activator

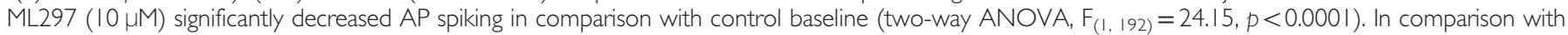
ML297 baseline, DA (c, two-way ANOVA, $F_{(1,144)}=16.59$, *** $<0.00 \mathrm{I}$ ) but not NE (d) or 5HT (e) produced a significant decrease in AP spiking. (f) Numbers of spikes at the highest current injection are compared as a percent change from ML297 baseline in response to each drug treatment condition. With ML297, DA further decreased spike firing and this decrease was significantly different from ML297 baseline (two-tail paired $t$-test, $t(9)=3.28$, *** $p=0.0095$ ). No difference in AP spiking was observed when NE (two-tail paired $t$-test, $t(6)=0.2247, p=0.8297$ ) or $5 \mathrm{HT}$ (two-tail paired $t$-test, $t(10)=1.881, p=0.0894)$ was added in the presence of ML297.

\section{Role of GIRK Channels in the Inhibitory Effects of Monoamines}

Many $\mathrm{G}_{\mathrm{i} \alpha}$-coupled receptors are linked to stimulation of GIRK (Kir3 family) channels that are major regulators of neuronal excitability (Dascal, 1997; Hille, 1992). As D2, $5 \mathrm{HT}_{1 \mathrm{~A}}$, and $\alpha 2$-adrenergic receptors are all $\mathrm{G}_{\mathrm{i} \alpha}$ coupled, we examined whether modulating GIRK channel activity would interfere with the inhibitory effects of monoamines. As shown in Figure 4a, a low concentration of barium $(100 \mu \mathrm{M})$ chosen to primarily inhibit GIRK channels (McDaid et al, 2008; Hurst et al, 1995; van Welie et al, 2005) produced a small, but significant, increase in AP spiking of lOFC neurons (two-way ANOVA, $\quad \mathrm{F}_{(1,560)}=27.2, \quad p<0.0001$; $N=30$ ). Data in Figure $4 \mathrm{~b}$ show the number of spikes at the highest current injection step $(220 \mathrm{pA})$ in the presence of barium and each monoamine $(50 \mu \mathrm{M})$ and are normalized to the barium baseline. No significant difference in spike number from barium control recordings was observed for dopamine (two-tail paired $t$-test, $t(4)=0.85, p=0.4438$ ), serotonin (two-tail paired $t$-test, $t(5)=0.86, p=0.4292$ ), or norepinephrine (two-tail paired $t$-test, $t(5)=1.52$, $p=0.1889$ ). We then tested whether ML297, a direct activator of GIRK channels, would decrease cell firing and whether it occluded the inhibitory effects of each monoamine. As shown in Figure 4c-e, ML297 $(10 \mu \mathrm{M}$, applied in 
a

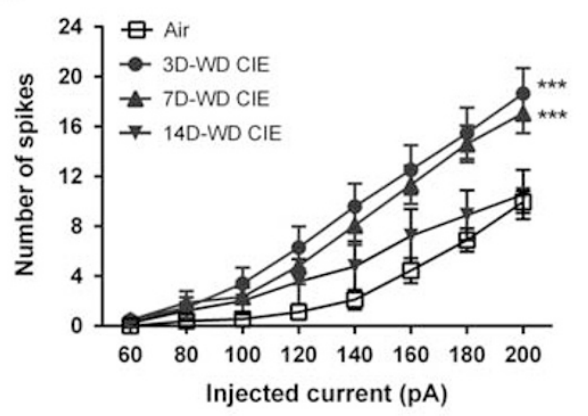

C

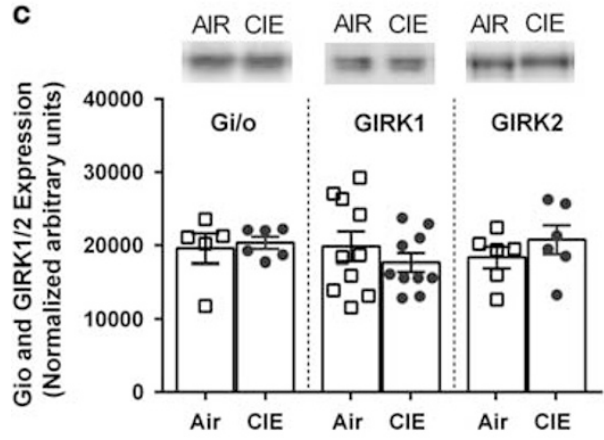

e

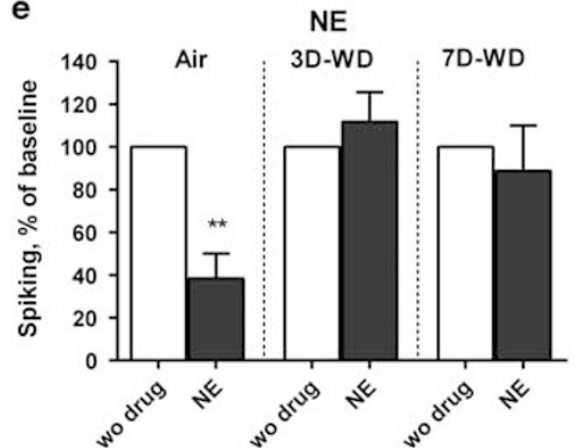

b

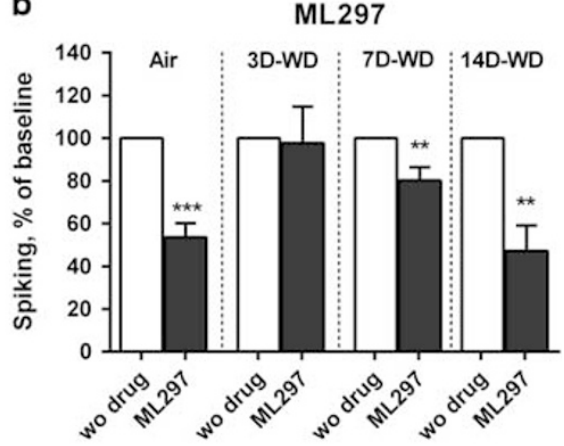

d

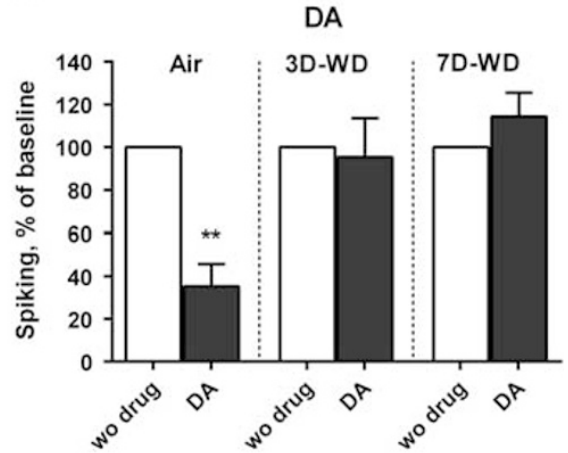

f

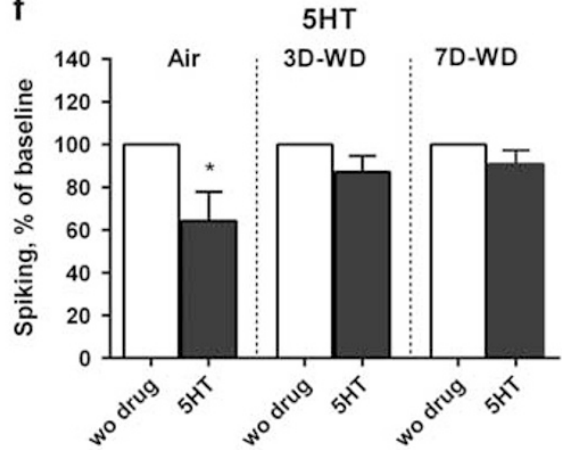

Figure 5 OFC neurons are hyperexcitable after withdrawal from CIE exposure and resistant to the inhibitory effects of the GIRK activator ML297 and monoamines. (a) Number (mean \pm SEM) of spikes from IOFC neurons from air- and ClE-treated mice plotted against a series of current injections (60200 pA). In comparison with air control, basal firing rates of IOFC neurons were significantly enhanced in 3-day withdrawal (3D-WD) and 7D-WD CIE groups (two-way ANOVA: main effect of $\mathrm{CIE}, \mathrm{F}_{(4,364)}=31.77$, ***** $<0.000$ I; post hoc comparison, air vs 3D-WD CIE **** $<<0.000$ I, air vs 7D-WD CIE ***** $p<0.000$ I). No difference in AP spiking between I4D-WD CIE and air control groups was observed ( $p>0.05$ ). (b) CIE exposure produced a significant decrease in ML297-induced inhibition in AP spiking at the 3-day withdrawal so that the mean number of spikes in the presence of ML297 did not differ from control baseline (two-tail paired $t$-test, $t(10)=0.1316, p=0.8979$ ). Significant inhibition by ML297 was observed in air-exposed mice (two-tail paired $t$-test, $t(I 6)=7.086$, **** $p<0.000 I$ ), 7D-WD (two-tail paired t-test, $t(17)=3.226$, $* * p=0.005$ ) and I 4D-WD (two-tail paired $t$-test, $t(7)=4.459$, $* * p=0.0029)$ CIE groups. (c) Representative western blots and optical density (mean $\pm \mathrm{SEM}$ ) of $\mathrm{G}_{\mathrm{i} / \mathrm{o}}$ protein and GIRK subunits in IOFC neurons from air and 3D-WD groups. No difference in expression of $\mathrm{G}_{\mathrm{i} / \mathrm{o}}$ (two-tailed $t$-test, $t(9)=0.3727, p=0.7 \mid 8$ ), GIRKI (two-tailed $t$-test, $t(10)=0.9863$, $p=0.3473$ ), or GIRK2 (two-tailed $t$ test, $t(\mid 8)=0.9218, p=0.3688$ ) protein between air- and 3D-WD CIE-exposed groups were observed. (d) DA caused a significant reduction in number of spikes in air control (two-tail paired $t$-test, $t(4)=6.236$, ${ }^{*} * p=0.0034$ ), but not in 3D-WD (two-tail paired $t$-test, $\left.t(5)=0.2606, p=0.8048\right)$ and 7D-WD (twotail paired $t$-test, $t(5)=1.266, p=0.2613$ ) ClE groups. (e) NE significantly reduced evoked spiking in air control (two-tail paired $t$-test, $t(6)=5.296$, *** $p=0.00$ I 8), but not in 3D-WD (two-tail paired $t$-test, $t(4)=0.8409, p=0.4477$ ) and 7D-WD (two-tail paired $t$-test, $t(3)=0.5315, p=0.6319) C I E$ groups. (f) A significant decrease in spiking by $5 \mathrm{HT}$ was observed in air control (two-tail paired $t$-test, $t(5)=2.626$, * $p=0.0467$ ), but not in 3D-WD (two-tail paired $t$ test, $t(4)=1.713, p=0.1619$ ) and 7D-WD (two-tail paired $t$-test, $t(4)=1.422, p=0.228)$ ClE groups. (b, $d-f)$ Numbers of spikes at the highest current injection are compared as percent change from control baseline (without drug) in response to each treatment condition.

the superfusate for $10 \mathrm{~min}$ ) significantly decreased firing as compared with the control drug-free baseline (two-way repeated measures ANOVA, $\mathrm{F}_{(1,43)}=64.78, p<0.0001$; $N=44$ ). Adding DA in the presence of ML297 (Figure 4c) further decreased spiking, whereas neither NE (Figure 4d) nor 5HT (Figure 4e) produced any additional decrease in firing as compared with the ML297 baseline. Summarized in Figure $4 \mathrm{f}$ are the number of spikes at the highest current injection step in the presence of ML297 and each monoamine (data from Figure $4 \mathrm{c}-\mathrm{e}$ ) and are normalized to the ML297 baseline. With ML297, spiking produced by NE (twotail paired $t$-test, $t(7)=0.4472, p=0.6682$ ) or $5 \mathrm{HT}$ (two-tail 
paired $t$-test, $t(10)=1.813, p=0.0998)$ was not different from spiking produced by ML297 alone. In contrast, DA further decreased AP spiking and this decrease was significantly different from ML297 baseline (two-tail paired $t$-test, $t(8)=4.6, p=0.0018)$. We then tested whether blocking G-protein activation prevents monoamine-induced inhibition of spiking. In the presence of GDP- $\beta$-S $(500 \mu \mathrm{M}$, applied intracellularly through patch pipette), 5HT $(50 \mu \mathrm{M})$ did not significantly inhibit cell firing (Supplementary Figure S2b and d; two-way repeated measures $\operatorname{ANOVA}, \mathrm{F}_{(9,54)}=1.689$, $p=0.1144 ; N=7)$. In contrast, DA $(50 \mu \mathrm{M})$ reduced currentevoked spiking in the presence of GDP- $\beta$-S (Supplementary Figure S2c and d; two-way repeated measures ANOVA, $\left.\mathrm{F}_{(9,54)}=4.946, p<0.0001 ; N=9\right)$, although the magnitude of inhibition was less than that without GDP- $\beta$-S in the pipette (see Figure 1a for comparison). GDP- $\beta$-S by itself had no effect on AP spiking over a $20 \mathrm{~min}$ time course (Supplementary Figure S2a, two-way repeated measures ANOVA, $\left.\mathrm{F}_{(18,90)}=0.8849, p=0.5975 ; N=6\right)$. Together with results from the barium and ML297 recordings, these findings are consistent with the idea that $\mathrm{G}_{\mathrm{i} / \mathrm{o}}$-coupled monoamine receptors reduce excitability of 1 OFC neurons via activation of GIRK channels and suggest the involvement of an additional non-GIRK mechanism in the inhibitory actions of DA.

\section{CIE Exposure Attenuates ML297 and Monoamine Inhibition of Firing}

We previously demonstrated that withdrawal from chronic intermittent ethanol treatment increases the excitability of IOFC neurons for up to 10 days after the last ethanol exposure (Nimitvilai et al, 2016). In the present study, we replicated this finding, added data from a 14-day withdrawal group, and examined whether CIE exposure alters monoamine inhibition of current-evoked spiking. As reported previously (Nimitvilai et al, 2016), CIE-exposed mice showed enhanced AP spiking as compared with air controls (Figure 5a; two-way ANOVA: main effect of CIE, $\left.\mathrm{F}_{(4,364)}=31.77, p<0.0001\right)$. The post hoc comparisons revealed significant differences in spiking for 3-day $(q=8.338, \quad p<0.0001 ; \quad N=17)$ and 7-day $(q=7.189$, $p<0.0001 ; N=15$ ) withdrawal (WD) groups. At 14 days after withdrawal, spiking from CIE-treated mice was not different from air controls $(q=0.771, p>0.05 ; N=9)$.

We then tested whether CIE exposure altered the inhibition of firing by direct activation of GIRK channels. Shown in Figure 5b are the number of spikes at the highest current injection step in the presence of ML297 that are normalized to control baseline (without drug). The GIRK activator ML297 $(10 \mu \mathrm{M})$ significantly decreased spiking in neurons from air-exposed mice (two-tail paired $t$-test, $t(16)=7.086, p<0.0001$ ), but had no effect on firing in IOFC neurons from the 3D-WD CIE group (two-tail paired $t$-test, $t(10)=0.1316, p=0.8979)$. In the 7D-WD group, inhibition of spiking by ML297 was significantly different from the control $(n=18$, two-tail paired $t$-test, $t(17)=3.226$, $p=0.005)$, but the level of inhibition was still less than that seen in neurons from air-exposed animals. By 14 days of withdrawal, ML297 inhibition of spiking was similar to that of air controls (two-tail paired $t$-test, $t(7)=4.459, p=0.0029$ ). Multiple GIRK channel subtypes have been identified, and in the brain, GIRK1, GIRK2, and GIRK3 subunits are moderately or highly expressed whereas that of GIRK4 is low or undetectable (Chan et al, 1997; Karschin et al, 1996; Kobayashi et al, 1995). The expressions of $G_{i}$ and $G_{o}$ proteins that link GPCRs to GIRKs are also highly expressed in brain including the frontal cortex (Cruz et al, 2008; Goodfellow et al, 2009, 2014; Saenz del Burgo et al, 2008). To determine whether CIE exposure alters the expression of these proteins, western blotting was performed using antibodies against $G_{i / o}$ protein subunits and GIRK channels including GIRK1 that is the target of ML297 (Days et al, 2010). At the 3-day WD time where ML297 had no effect on firing, air- and CIE-treated mice expressed similar amounts of $\mathrm{G}_{\mathrm{i} / \mathrm{o}}$ proteins (two-tailed $t$-test, $t(9)=0.3727, p=0.718$ ), GIRK1 (two-tailed $t$-test, $t(10)=0.9863, p=0.3473$ ), and GIRK2 (two-tailed $t$-test, $t(18)=0.9218, p=0.3688$ ) channel subunits (Figure $5 c$ ).

Although CIE exposure blunted the inhibitory effect of the direct channel activator ML297 on OFC neuron firing, no changes in expression of $\mathrm{G}_{\mathrm{i} / \mathrm{o}}$ or GIRK channel subunits were observed, suggesting that receptor-mediated effects on excitability might be unaffected. Thus, in an additional set of air- and CIE-treated mice, we tested the effect of DA, NE and $5 \mathrm{HT}$ on current-evoked spiking of $1 \mathrm{OFC}$ neurons. As previously observed (Figures 1 and 2), AP spiking was significantly reduced by DA (Figure $5 \mathrm{~d}$; two-tail paired $t$-test, $t(4)=6.236, p=0.0034$ ), NE (Figure 5e; two-tail paired $t$-test, $t(6)=5.296, p=0.0018$ ), or 5HT (Figure 5f; two-tail paired $t$-test, $t(5)=2.626, p=0.0467)$ in neurons from air control groups. However, DA, NE, and 5HT inhibition of evoked firing was completely abolished in neurons from CIE-treated mice (Figures 5d-f, respectively). Unlike that found for ML297, the loss of monoamine inhibition of excitability persisted for up to 7 days following withdrawal from CIE exposure.

\section{DISCUSSION}

We reported previously that ethanol, applied acutely, reduces the intrinsic excitability of IOFC neurons (Badanich et al, 2013), and that firing is enhanced in alcohol-dependent mice (Nimitvilai et al, 2016). The results of the present study demonstrate that the enhanced excitability of lOFC neurons in CIE-treated mice is accompanied by a loss of monoamine inhibition of firing normally observed in control animals. Specifically, DA, NE, and 5HT each decreased currentevoked firing of IOFC neurons from control animals and results from pharmacological studies suggest that this action was mediated primarily via $\mathrm{G}_{\mathrm{i} \alpha}$-coupled $\mathrm{D} 2, \alpha 2$, and $5 \mathrm{HT}_{1 \mathrm{~A}}$ receptors, respectively. These receptors all stimulate inhibitory GIRK channels consistent with the findings showing that the GIRK channel blocker barium occluded monoamine-induced inhibition of firing and that ML297, a direct GIRK channel activator, itself reduced firing. Overall, these results suggest that monoamines likely play a key role in modulating the intrinsic excitability of lOFC neurons and that loss of this action following chronic ethanol exposure may contribute to the impairment of OFC-dependent behaviors observed in alcohol-dependent individuals.

In this study, 1OFC neurons from CIE mice were resistant to monoamine or ML297-induced inhibition of firing and this occurred in the absence of obvious changes in GIRK1, 
GIRK2, or $\mathrm{G}_{\mathrm{i} / \mathrm{o}}$ subunit expression. Although we cannot rule out that there may have been local or cell-type-specific changes in these proteins that may have been missed in the tissue punch samples, these findings suggest that CIE may induce changes in monoamine receptors or in processes that couple these receptors to their GIRK and G-protein counterparts. Although possible, it seems unlikely that CIE could cause identical changes in the expression of specific $\mathrm{G}_{\mathrm{i}}$-linked monoamine receptors among three different neurotransmitter families, suggesting that downstream events common to each of these receptors may be a more likely site of action. GIRK channels (Huang et al, 1998; Xiao et $a l, 2003)$ and some members of the transient receptor potential family (Huang et al, 1998; Xiao et al, 2003) require the membrane-associated phosphatidylinositol-4,5-bisphosphate (PIP2) for activation or regulation. Acute ethanol modulation of these channels has been shown to be sensitive to manipulations in PIP2 (Huang et al, 1998; Xiao et al, 2003) and following CIE, PIP2 activation of phospholipase C in NG108 neuroglia cells to ethanol is blunted (Katsura et al, 1994; Pandey, 1996). Similar findings have been reported in ethanol-dependent mice (Katsura et al, 1994; Pandey, 1996). Chronic ethanol exposure and withdrawal has also been shown to upregulate the expression of calmodulin (Katsura et al, 1994; Pandey, 1996), phospholipase C, and selective protein kinase C isozymes (Katsura et al, 1994; Pandey, 1996) in several brain regions and cultured neurons. Upregulation of these signaling molecules is linked to destabilization of GIRK-PIP2 interactions and PIP2 depletion on channel activity (Katsura et al, 1994; Pandey, 1996). Although not measured in this study, depletion or uncoupling of PIP2 from its downstream targets could account for the global loss of GIRK channel function in CIE-treated animals even though overall channel expression was not changed. Interestingly, the loss of monoamine inhibition in CIE-treated mice persisted for at least 1 week, whereas the ability of ML297 to reduce firing recovered by the 7-day WD period. This differential recovery of action suggests that the loss of monoamine inhibition of excitability following CIE exposure may involve multiple sites in the receptor/G-protein/GIRK channel cascade that links monoamines to control of firing. In addition, we reported previously that acute ethanol reduces firing of 1 OFC neurons via activation of ionotropic glycine receptors (Badanich et al, 2013) and that following CIE exposure, this effect is lost along with a blunting of inhibition by the glycine transport inhibitor sarcosine, reduced expression of the GlyT1 transporter, and a functional downregulation of small conductance (SK) potassium channels (Nimitvilai et al, 2016). When combined with the findings of the current study, these results demonstrate that CIE exposure and withdrawal induces time-dependent changes in multiple mediators of $1 \mathrm{OFC}$ excitability that renders these neurons hyperexcitable. Restoring control over firing of OFC neurons in ethanoldependent subjects thus likely requires the targeting of multiple neurotransmitter systems and effectors.

Whereas the effects of $\mathrm{NE}$ and 5HT on $1 \mathrm{HFC}$ firing appeared to result from activation of GIRK channels, the actions of DA were more complex. Both DA and a specific D2 receptor agonist quinpirole decreased spike firing in IOFC neurons, and these effects were blocked by picrotoxin, suggesting the involvement of $\mathrm{GABA}_{\mathrm{A}}$ receptors. Many studies have reported on DA ability to modulate synaptic GABA-mediated inhibition in the PFC, with some reporting a D2-mediated decrease in GABA release (Retaux et al, 1991) or evoked GABAergic synaptic response (Penit-Soria et al, 1989) and others showing increases in extracellular GABA (Grobin and Deutch, 1998) or GABAergic sIPSCs (PenitSoria et al, 1987; Zhou and Hablitz, 1999) following exposure to a D2 agonist. In the adult but not juvenile rat PFC, activation of D2 receptors enhances the firing of fast-spiking interneurons that inhibit pyramidal neuron excitability (Gorelova et al, 2002; Williams and Goldman-Rakic, 1995) and D1-mediated activation of GABAergic interneurons results in attenuation of spontaneous PFC neuronal firing (Gorelova et al, 2002; Williams and Goldman-Rakic, 1995). $\mathrm{DA}$ also has effects on extrasynaptic $\mathrm{GABA}_{\mathrm{A}}$ receptors that generate a tonic inhibitory current in various brain regions. For example, in nucleus accumbens medium spiny neurons (MSNs), activation of D1 receptors increases tonic current, whereas acute or prolonged activation of D2 receptors has no effect or decreases tonic current, respectively (Maguire et al, 2014). In the dorsal striatum, the effect of DA on tonic current is age dependent, mediated mainly by the $\alpha 5$ GABA subunit in D2-MSNs in immature mice and by the $\delta$-subunit in D1-MSNs in mature animals (Ade et al, 2008; Janssen et al, 2009; Santhakumar et al, 2010). In the 1OFC of adult rats, D1 receptor activation increases the amplitude of NMDA EPSCs and D2 receptor agonists decrease NMDA EPSCs (Thompson et al, 2016). In contrast, Wallace et al (2014) reported that DA had no effect on mono- or polysynaptic responses of electrically evoked field responses recorded from slices containing caudal areas of the OFC. In this study, we found that DA or the D1 agonist SKF81297 had no effect on sIPSCs but increased a tonic current that was suppressed by picrotoxin. In contrast, the D2 agonist quinpirole increased sIPSC amplitude but had no effect on GABA-mediated tonic inhibition. Although both D1- and D2-mediated events would be expected to reduce excitability, blocking D1 receptors did not prevent DA inhibition of current-evoked spiking, whereas picrotoxin prevented inhibition of firing by either DA or the D2 agonist quinpirole. D2 activation of fast-spiking interneurons in the 1OFC, similar to that found in adult rat mPFC (Gorelova et al, 2002; Williams and Goldman-Rakic, 1995), could explain these results, although the effects of DA on spiking were also blocked by barium suggesting a direct postsynaptic GIRKmediated mechanism. In addition, unlike NE or 5HT, DA induced an additional inhibition of firing in the presence of the direct GIRK channel activator ML297 or the G-protein blocker GDP- $\beta-\mathrm{S}$, again suggesting multiple mechanisms for DA modulation of OFC firing. How these actions influence monoamine regulation of OFC activity in vivo is not yet clear, although results from studies using indirect monoamine agonists suggest that both increases and decreases can occur. For example, OFC spiking measured in vivo was mainly enhanced following experimenter administered amphetamine (Homayoun and Moghaddam, 2008), whereas bidirectional changes in OFC spiking were observed in rats that received cocaine noncontingently or via selfadministration or during presentation of cocaine-predictive cues (Guillem et al, 2010). These results suggest that both local and circuit-based mechanisms ultimately determine the 
net result of monoamine receptor activation on OFC neuron firing.

We note that in the present study, micromolar concentrations of DA, NE, and $5 \mathrm{HT}$ were required to alter firing of IOFC neurons, similar to findings reported for other cortical areas (Di Pietro and Seamans, 2011; Gonzalez-Islas and Hablitz, 2001; Nimitvilai et al, 2012; Trantham-Davidson et al, 2014; Wallace et al, 2014) and for the OFC (Wallace et al, 2014). However, extracellular concentrations of monoamines in the PFC are estimated to be in the nanomolar range (Mallo et al, 2008; Moghaddam et al, 1990), calling into question the physiological relevance of the high concentrations used in brain slice studies. This apparent discrepancy may reflect active uptake of monoamines, and/ or the slow penetration of these substances into the relatively thick $(\sim 300 \mu \mathrm{m})$ slices used in these experiments. Although both NE transporters and serotonin transporters appear to be highly expressed in the PFC (Morón et al, 2002), expression of the DA transporters is minimal (Freed et al, 1995; Sesack et al, 1998). Nevertheless, DA in the PFC can be broken down by enzymatic means (catechol-O-methyltransferase) and DA is actively taken up by the other monoamine transporters, especially that for NE (Di Chiara et al, 1992; Morón et al, 2002; Mundorf et al, 2001; Pani et al, 1990; Yamamoto and Novotney, 1998). In the present study, dopamine applied in the presence of a concentration of the nonspecific monoamine transporter inhibitor predicted to block all monoamine transporters (Tuomisto, 1977) significantly decreased lOFC neuronal firing at concentrations as low as $1-100 \mathrm{nM}$. These findings suggest that active transport regulates extracellular levels of monoamines even in acute slices of the OFC. As there is evidence for an increase in monoamine uptake rate following CIE (Di Chiara et al, 1992; Yamamoto and Novotney, 1998) and inhibition of monoamine transporter attenuates excessive drinking and impulsivity in high-alcohol-preferring animals (Di Chiara et al, 1992; Yamamoto and Novotney, 1998), it will be important to determine whether CIE also affects monoamine transporter activity in the OFC.

Imbalance or dysfunction of monoamine neurotransmission has been linked to functional abnormalities in the OFC and deficits in behavioral flexibility that require an intact OFC (Pardey et al, 2013; Wischhof et al, 2011; Zeeb et al, 2010). For example, low levels of serotonin within the OFC impaired performance on a visual discrimination reversal task in marmosets and rodents (Clarke et al, 2004; Masaki et al, 2006), and caused disruption on a detour reaching task in monkeys (Walker et al, 2006). In addition, animals receiving systemic administration of haloperidol, a potent DA receptor blocker with higher affinity for D2-like receptors, or the D2/D3 receptor antagonist raclopride, require more trials and produce more errors in order to reach the performance criterion in the reversal (Ridley et al, 1981; Lee et al, 2007). Reductions in D2 receptors have also been associated in alcoholism and other substance abuse disorders (Noble, 2000). We reported previously that ethanol-dependent mice exhibit deficits in reversal learning (Badanich et al, 2011) and drink more alcohol compared with control animals (den Hartog et al, 2016). The present study showed that CIE induced a loss of D2, $5 \mathrm{HT}_{1 \mathrm{~A}}$, and $\alpha 2$ receptor modulation of intrinsic excitability, suggesting that a loss of monoamine receptor activity within the OFC would be expected to adversely impact the organization of neural networks and cognitive functions mediated by each monoamine, and thus may play a role in behavioral inflexibility and cognitive deficits associated with chronic alcohol exposure.

In conclusion, the results of the present study suggest that monoamines may play a key role in regulating the intrinsic excitability of IOFC neurons, through modulation of GABAmediated events and activation of $\mathrm{G}_{\mathrm{i} \alpha}$-coupled GIRK channels (summarized in a model; Supplementary Figure S3). Maintaining optimal levels of monoamine signaling is likely critical for support of cognitive functions that require an intact $\mathrm{OFC}$ and loss of these regulatory processes may contribute to the pathology of various neuropsychiatric disorders including schizophrenia, obsessive-compulsive disorder, as well as alcohol and substance abuse disorders. The profound loss of DA-, NE-, and 5HT-mediated control of lOFC excitability following CIE exposure also suggests that treatments focused on specific receptor subtypes may not be effective in restoring the balance of monoamine signaling in alcohol-dependent individuals especially during the early stages of abstinence.

\section{FUNDING AND DISCLOSURE}

This work was supported by P50AA010761 and R37AA009986 to JJW; UO1 AA020929 to MFL; and U01AA020930 to PJM. The authors declare no conflict of interest.

\section{REFERENCES}

Ade KK, Janssen MJ, Ortinski PI, Vicini S (2008). Differential tonic GABA conductances in striatal medium spiny neurons. J Neurosci 28: 1185-1197.

Agster KL, Mejias-Aponte CA, Clark BD, Waterhouse BD (2013). Evidence for a regional specificity in the density and distribution of noradrenergic varicosities in rat cortex. J Comp Neurol 521: 2195-2207.

Badanich K, Mulholland P, Beckley J, Trantham-Davidson H, Woodward J (2013). Ethanol reduces neuronal excitability of lateral orbitofrontal cortex neurons via a glycine receptor dependent mechanism. Neuropsycopharmacology 38: 1176-1188.

Badanich KA, Becker HC, Woodward JJ (2011). Effects of chronic intermittent ethanol exposure on orbitofrontal and medial prefrontal cortex-dependent behaviors in mice. Behav Neurosci 125: 879-891.

Bissonette GB, Martins GJ, Franz TM, Harper ES, Schoenbaum G, Powell EM (2008). Double dissociation of the effects of medial and orbital prefrontal cortical lesions on attentional and affective shifts in mice. J Neurosci 28: 11124-11130.

Brown KL, Calizo LH, Goodlett CR, Stanton ME (2007). Neonatal alcohol exposure impairs acquisition of eyeblink conditioned responses during discrimination learning and reversal in weanling rats. Dev Psychobiol 49: 243-257.

Chan KW, Sui JL, Vivaudou M, Logothetis DE (1997). Specific regions of heteromeric subunits involved in enhancement of $\mathrm{G}$ protein-gated K+ channel activity. J Biol Chem 272: 6548-6555.

Clarke HF, Dalley JW, Crofts HS, Robbins TW, Roberts AC (2004). Cognitive inflexibility after prefrontal serotonin depletion. Science 304: 878-880.

Clarke HF, Walker SC, Crofts HS, Dalley JW, Robbins TW, Roberts AC (2005). Prefrontal serotonin depletion affects reversal learning but not attentional set shifting. J Neurosci 25: 532-538. 
Cruz HG, Berton F, Sollini M, Blanchet C, Pravetoni M, Wickman K et al (2008). Absence and rescue of morphine withdrawal in GIRK/Kir3 knock-out mice. J Neurosci 28: 4069-4077.

Dascal N (1997). Signalling via the G protein-activated K+ channels. Cell Signal 9: 551-573.

Days E, Kaufmann K, Romaine I, Niswender C, Lewis M, Utley T et al (2010). Discovery and characterization of a selective activator of the G-protein activated inward-rectifying potassium (GIRK) channel. Probe Reports from the NIH Molecular Libraries Program, Bethesda, MD, USA.

den Hartog C, Zamudio-Bulcock P, Nimitvilai S, Gilstrap M, Eaton B, Fedarovich $\mathrm{H}$ et al (2016). Inactivation of the lateral orbitofrontal cortex increases drinking in ethanol-dependent but not nondependent mice. Neuropsychopharmacology 107: 451-459.

Di Chiara G, Tanda GL, Frau R, Carboni E (1992). Heterologous monoamine reuptake: lack of transmitter specificity of neuronspecific carriers. Neurochem Int 20: 231S-235S.

Di Pietro NC, Seamans JK (2011). Dopamine and serotonin interactively modulate prefrontal cortex neurons in vitro. Biol Psychiatry 69: 1204-1211.

Fortier CB, Steffen EM, Lafleche G, Venne JR, Disterhoft JF, McGlinchey RE (2008). Delay discrimination and reversal eyeblink classical conditioning in abstinent chronic alcoholics. Neuropsychology 22: 196-208.

Freed C, Revay R, Vaughan RA, Kriek E, Grant S, Uhl GR et al (1995). Dopamine transporter immunoreactivity in rat brain. $J$ Comp Neurol 359: 340-349.

Gonzalez-Islas C, Hablitz JJ (2001). Dopamine inhibition of evoked IPSCs in rat prefrontal cortex. J Neurophysiol 86: 2911-2918.

Goodfellow NM, Benekareddy M, Vaidya VA, Lambe EK (2009). Layer II/III of the prefrontal cortex: Inhibition by the serotonin 5HT1A receptor in development and stress. J Neurosci 29: 10094-10103.

Goodfellow NM, Sargin D, Ansorge MS, Gingrich JA, Lambe EK (2014). Mice with compromised 5-HTT function lack phosphotyrosine-mediated inhibitory control over prefrontal 5HT responses. J Neurosci 34: 6107-6111.

Gorelova N, Seamans JK, Yang CR (2002). Mechanisms of dopamine activation of fast-spiking interneurons that exert inhibition in rat prefrontal cortex. $J$ Neurophysiol 88: 3150-3166.

Grobin AC, Deutch AY (1998). Dopaminergic regulation of extracellular gamma-aminobutyric acid levels in the prefrontal cortex of the rat. J Pharmacol Exp Ther 285: 350-357.

Guillem K, Kravitz AV, Moorman DE, Peoples LL (2010). Orbitofrontal and insular cortex: neural responses to cocaineassociated cues and cocaine self-administration. Synapse 64: 1-13.

Hille B (1992). G protein-coupled mechanisms and nervous signaling. Neuron 9: 187-195.

Hoerbelt P, Lindsley TA, Fleck MW (2015). Dopamine directly modulates GABAA receptors. J Neurosci 35: 3525-3536.

Homayoun H, Moghaddam B (2008). Orbitofrontal cortex neurons as a common target for classic and glutamatergic antipsychotic drugs. Proc Natl Acad Sci USA 105: 18041-18046.

Huang CL, Feng S, Hilgemann DW (1998). Direct activation of inward rectifier potassium channels by PIP2 and its stabilization by Gbetagamma. Nature 391: 803-806.

Hurst RS, Latorre R, Toro L, Stefani E (1995). External barium block of Shaker potassium channels: evidence for two binding sites. $J$ Gen Physiol 106: 1069-1087.

Janssen MJ, Ade KK, Fu Z, Vicini S (2009). Dopamine modulation of GABA tonic conductance in striatal output neurons. J Neurosci 29: $5116-5126$.

Jedema HP, Carter MD, Dugan BP, Gurnsey K, Olsen AS, Bradberry CW (2011). The acute impact of ethanol on cognitive performance in rhesus macaques. Cereb Cortex 21: 1783-1791.

Karschin C, Dissmann E, Stuhmer W, Karschin A (1996). IRK(1-3) and GIRK(1-4) inwardly rectifying $\mathrm{K}+$ channel mRNAs are differentially expressed in the adult rat brain. J Neurosci 16: 3559-3570.

Katsura M, Ohkuma S, Chen DZ, Kuriyama K (1994). Ethanolinduced alteration in activities of cerebral phosphatidylinositol 4,5-biphosphate-specific and cytosolic phospholipase $\mathrm{C}$ in the brain: analysis using NG 108-15 cells and brains from ethanolinhaled mice. Neurochem Int 24: 541-547.

Kheramin S, Body S, Ho MY, Velazquez-Martinez DN, Bradshaw CM, Szabadi E et al (2004). Effects of orbital prefrontal cortex dopamine depletion on inter-temporal choice: a quantitative analysis. Psychopharmacology (Berl) 175: 206-214.

Kirby LG, Zeeb FD, Winstanley CA (2011). Contributions of serotonin in addiction vulnerability. Neuropharmacology 61: 421-432.

Kobayashi T, Ikeda K, Ichikawa T, Abe S, Togashi S, Kumanishi T (1995). Molecular cloning of a mouse G-protein-activated K+ channel (mGIRK1) and distinct distributions of three GIRK (GIRK1, 2 and 3) mRNAs in mouse brain. Biochem Biophys Res Commun 208: 1166-1173.

Lee B, Groman S, London ED, Jentsch JD (2007). Dopamine D2/D3 receptors play a specific role in the reversal of a learned visual discrimination in monkeys. Neuropsychopharmacology 32: 2125-2134.

Maguire EP, Macpherson T, Swinny JD, Dixon CI, Herd MB, Belelli D et al (2014). Tonic inhibition of accumbal spiny neurons by extrasynaptic alpha4betadelta GABAA receptors modulates the actions of psychostimulants. J Neurosci 34: 823-838.

Mallo T, Koiv K, Koppel I, Raudkivi K, Uustare A, Rinken A et al (2008). Regulation of extracellular serotonin levels and brainderived neurotrophic factor in rats with high and low exploratory activity. Brain Res 1194: 110-117.

Masaki D, Yokohama C, Kinoshita S, Tsuchida H, Nakatomi Y, Yoshimoto K et al (2006). Relationship between limbic and cortical 5-HT neurotransmission and acquisition and reversal learning in a go/no-go task in rats. Psychopharmacology (Berl) 189: 249-258.

McAlonan K, Brown VJ (2003). Orbital prefrontal cortex mediates reversal learning and not attentional set shifting in the rat. Behav Brain Res 146: 97-103.

McDaid J, McElvain MA, Brodie MS (2008). Ethanol effects on dopaminergic ventral tegmental area neurons during block of Ih: involvement of barium-sensitive potassium currents. J Neurophysiol 100: 1202-1210.

McGuier N, Padula A, Lopez M, Woodward J, Mulholland P (2015). Withdrawal from chronic intermittent alcohol exposure increases dendritic spine density in the lateral orbitofrontal cortex in mice. Alcohol 49: 21-27.

Moghaddam B, Roth RH, Bunney BS (1990). Characterization of dopamine release in the rat medial prefrontal cortex as assessed by in vivo microdialysis: comparison to the striatum. Neuroscience 36: 669-676.

Morón JA, Brockington A, Wise RA, Rocha BA, Hope BT (2002). Dopamine uptake through the norepinephrine transporter in brain regions with low levels of the dopamine transporter: evidence from knock-out mouse lines. J Neurosci 22: 389-395.

Mundorf ML, Joseph JD, Austin CM, Caron MG, Wightman RM (2001). Catecholamine release and uptake in the mouse prefrontal cortex. J Neurochem 79: 130-142.

Narendran R, Mason NS, Paris J, Himes ML, Douaihy AB, Frankle WG (2014). Decreased prefrontal cortical dopamine transmission in alcoholism. Am J Psychiatry 171: 881-888.

Nimitvilai S, Arora DS, Brodie MS (2012). Reversal of dopamine inhibition of dopaminergic neurons of the ventral tegmental area is mediated by protein kinase C. Neuropsychopharmacology 37: 543-556.

Nimitvilai S, Lopez M, Mulholland P, Woodward J (2016). Chronic intermittent ethanol exposure enhances the excitability and synaptic plasticity of lateral orbitofrontal cortex neurons and induces a tolerance to the acute inhibitory actions of ethanol. Neuropsypharmacology 41: 1112-1127. 
Noble EP (2000). The DRD2 gene in psychiatric and neurological disorders and its phenotypes. Pharmacogenomics 1: 309-333.

Pandey SC (1996). Acute and chronic ethanol consumption effects on the immunolabeling of $\mathrm{Gq} / 11$ alpha subunit protein and phospholipase $\mathrm{C}$ isozymes in the rat brain. J Neurochem 67: 2355-2361.

Pani L, Carboni S, Kusmin A, Gessa G, Rossetti Z (1990). Nimodipine inhibits cocaine-induced dopamine release and motor stimulation. Eur J Pharmacol 176: 245-246.

Pardey MC, Kumar NN, Goodchild AK, Cornish JL (2013). Catecholamine receptors differentially mediate impulsive choice in the medial prefrontal and orbitofrontal cortex. $J$ Psychopharmacol 27: 203-212.

Penit-Soria J, Audinat E, Crepel F (1987). Excitation of rat prefrontal cortical neurons by dopamine: an in vitro electrophysiological study. Brain Res 425: 263-274.

Penit-Soria J, Retaux S, Maurin Y (1989). [Effects of the stimulation of D1 and D2 dopaminergic receptors on the electrically induced release of gamma- $(3 \mathrm{H})$-aminobutyric acid in the prefrontal cortex of the rat]. C R Acad Sci III 309: 441-446.

Rainnie DG (1999). Serotonergic modulation of neurotransmission in the rat basolateral amygdala. J Neurophysiol 82: 69-85.

Retaux S, Besson MJ, Penit-Soria J (1991). Opposing effects of dopamine D2 receptor stimulation on the spontaneous and the electrically evoked release of $[3 \mathrm{H}] \mathrm{GABA}$ on rat prefrontal cortex slices. Neuroscience 42: 61-71.

Ridley RM, Haystead TA, Baker HF (1981). An analysis of visual object reversal learning in the marmoset after amphetamine and haloperidol. Pharmacol Biochem Behav 14: 345-351.

Robbins TW, Arnsten AF (2009). The neuropsychopharmacology of fronto-executive function: monoaminergic modulation. Annu Rev Neurosci 32: 267-287.

Roesch MR, Olson CR (2007). Neuronal activity related to anticipated reward in frontal cortex: does it represent value or reflect motivation? Ann N Y Acad Sci 1121: 431-446.

Rothman RB, Blough BE, Baumann MH (2008). Dual dopamine/ serotonin releasers: potential treatment agents for stimulant addiction. Exp Clin Psychopharmacol 16: 458-474.

Saenz del Burgo L, Cortes R, Mengod G, Zarate J, Echevarria E, Salles J (2008). Distribution and neurochemical characterization of neurons expressing GIRK channels in the rat brain. $J$ Comp Neurol 510: 581-606.

Santhakumar V, Jones RT, Mody I (2010). Developmental regulation and neuroprotective effects of striatal tonic GABAA currents. Neuroscience 167: 644-655.

Schoenbaum G, Chiba AA, Gallagher M (1998). Orbitofrontal cortex and basolateral amygdala encode expected outcomes during learning. Nat Neurosci 1: 155-159.

Sesack SR, Hawrylak VA, Guido MA, Levey AI (1998). Cellular and subcellular localization of the dopamine transporter in rat cortex. Adv Pharmacol 42: 171-174.

Thompson JL, Yang J, Lau B, Liu S, Baimel C, Kerr LE et al (2016). Age-dependent D1-D2 receptor coactivation in the lateral orbitofrontal cortex potentiates NMDA receptors and facilitates cognitive flexibility. Cereb Cortex 26: 4524-4539.

Trantham-Davidson H, Burnett EJ, Gass JT, Lopez MF, Mulholland PJ, Centanni SW et al (2014). Chronic alcohol disrupts dopamine receptor activity and the cognitive function of the medial prefrontal cortex. J Neurosci 34: 3706-3718.

Tremblay L, Schultz W (1999). Relative reward preference in primate orbitofrontal cortex. Nature 398: 704-708.

Tuomisto J (1977). Nomifensine and its derivatives as possible tools for studying amine uptake. Eur J Pharmacol 42: 101-106.

van Welie I, Wadman WJ, van Hooft JA (2005). Low affinity block of native and cloned hyperpolarization-activated Ih channels by Ba2+ ions. Eur J Pharmacol 507: 15-20.

Verdejo-Garcia A, Bechara A, Recknor EC, Perez-Garcia M (2006). Executive dysfunction in substance dependent individuals during drug use and abstinence: an examination of the behavioral, cognitive and emotional correlates of addiction. J Int Neuropsychol Soc 12: 405-415.

Volkow ND, Chang L, Wang GJ, Fowler JS, Ding YS, Sedler M et al (2001). Low level of brain dopamine D2 receptors in methamphetamine abusers: association with metabolism in the orbitofrontal cortex. Am J Psychiatry 158: 2015-2021.

Volkow ND, Fowler JS, Wang GJ, Ding YS, Gatley SJ (2002). Role of dopamine in the therapeutic and reinforcing effects of methylphenidate in humans: results from imaging studies. Eur Neuropsychopharmacol 12: 557-566.

Walker SC, Mikheenko YP, Argyle LD, Robbins TW, Roberts AC (2006). Selective prefrontal serotonin depletion impairs acquisition of a detour-reaching task. Eur J Neurosci 23: 3119-3123.

Wallace J, Jackson RK, Shotton TL, Munjal I, McQuade R, Gartside SE (2014). Characterization of electrically evoked field potentials in the medial prefrontal cortex and orbitofrontal cortex of the rat: modulation by monoamines. Eur Neuropsychopharmacol 24: 321-332.

Wang DS, Mangin JM, Moonen G, Rigo JM, Legendre P (2006). Mechanisms for picrotoxin block of alpha2 homomeric glycine receptors. J Biol Chem 281: 3841-3855.

Williams GV, Goldman-Rakic PS (1995). Modulation of memory fields by dopamine D1 receptors in prefrontal cortex. Nature 376: 572-575.

Winstanley CA, Theobald DE, Dalley JW, Cardinal RN, Robbins TW (2006). Double dissociation between serotonergic and dopaminergic modulation of medial prefrontal and orbitofrontal cortex during a test of impulsive choice. Cereb Cortex 16: 106-114.

Wischhof L, Hollensteiner KJ, Koch M (2011). Impulsive behaviour in rats induced by intracortical DOI infusions is antagonized by co-administration of an mGlu2/3 receptor agonist. Behav Pharmacol 22: 805-813.

Xiao J, Zhen XG, Yang J (2003). Localization of PIP2 activation gate in inward rectifier K+ channels. Nat Neurosci 6: 811-818.

Yamamoto BK, Novotney S (1998). Regulation of extracellular dopamine by the norepinephrine transporter. J Neurochem 71: 274-280.

Zeeb FD, Floresco SB, Winstanley CA (2010). Contributions of the orbitofrontal cortex to impulsive choice: interactions with basal levels of impulsivity, dopamine signalling, and rewardrelated cues. Psychopharmacology (Berl) 211: 87-98.

Zhou FM, Hablitz JJ (1999). Dopamine modulation of membrane and synaptic properties of interneurons in rat cerebral cortex. $J$ Neurophysiol 81: 967-976.

Supplementary Information accompanies the paper on the Neuropsychopharmacology website (http://www.nature.com/npp) 